\title{
Cytotoxic effects of chemokine receptor 4 inhibition by AMD3100 in biliary tract cancer cells: Potential drug synergism with gemcitabine
}

\author{
CHRISTIAN MAYR ${ }^{1}$, DANIEL NEUREITER ${ }^{2}$, MARTIN PICHLER $^{3}$, FRIEDER BERR $^{1}$, \\ ANDREJ WAGNER ${ }^{1}$, TOBIAS KIESSLICH ${ }^{1,4}$ and KONRAD NAMBERGER ${ }^{5}$
}

\begin{abstract}
${ }^{1}$ Department of Internal Medicine I; ${ }^{2}$ Institute of Pathology, Paracelsus Medical University/Salzburger Landeskliniken, Salzburg A-5020, Austria; ${ }^{3}$ Department of Experimental Therapeutics, UT MD Anderson Cancer Center, Houston, TX 77054, USA; ${ }^{4}$ Laboratory for Tumour Biology and Experimental Therapies, Institute of Physiology and Pathophysiology, Paracelsus Medical University, Salzburg A-5020, Austria; ${ }^{5}$ Department of Hematology and Oncology, Klinikum Braunschweig, Braunschweig D-38118, Germany
\end{abstract}

Received July 14, 2014; Accepted February 27, 2015

DOI: $10.3892 / \mathrm{mmr} .2015 .3589$

\begin{abstract}
Biliary tract cancer (BTC) remains one of the most life-threatening types of cancer due to the lack of efficient therapies. Advanced tumour stages at the point of diagnosis and high chemoresistance are two of the predominant reasons for a 5 -year survival rate of only $\sim 5 \%$. The present study investigated the effect of the chemokine receptor 4 (CXCR4) inhibitor AMD3100 (Plerixafor), alone and in combination with standard gemcitabine chemotherapy, on the proliferation of BTC cells. The expression of CXCR4 was analysed by reverse transcription-quantitative polymerase chain reaction in eight heterogeneously differentiated BTC cell lines. The effects of treatment with the CXCR4 antagonist, AMD3100, on cell viability and anchorage-independent growth, and the possible synergistic cytotoxic effects of AMD3100 with standard chemotherapeutics were assessed. The expression of CXCR4 was observed to a variable extent in all eight BTC cell lines, with SkChA-1 cells exhibiting the highest expression levels. Treatment with AMD3100 led to a marginal decrease in cell viability in the cell lines, with the exception of the CCSW-1 cells, and a significant reduction in the GBC, MzChA-1, SkChA.-1 and TFK-1 cell lines. The combined treatment of the SkChA-1 cells with varying concentrations of AMD3100 and standard gemcitabine chemotherapy revealed a more marked overall cytotoxicity, indicating a potential
\end{abstract}

Correspondence to: $\mathrm{Dr}$ Tobias Kiesslich, Department of Internal Medicine I, Paracelsus Medical University/Salzburger Landeskliniken, 48 Muellner Haupstrasse, Salzburg A-5020, Austria E-mail: t.kiesslich@salk.at

Key words: biliary tract cancer, chemokine receptor 4, AMD3100, Plerixafor, viability, combination treatment, gemcitabine, anchorage-independent growth synergistic effect. In addition, AMD3100 significantly reduced anchorage-independent growth in the SkChA-1 cells. Overall, the results of the present study suggest that the inhibition of CXCR4 by AMD3100, in combination with gemcitabine, may be a suitable strategy for the future therapy of BTC.

\section{Introduction}

Biliary tract cancer (BTC) is a highly aggressive and heterogeneous type of cancer, originating in the bile ducts, with high rates of relapse and poor clinical outcome (1). Despite current treatment strategies, including surgery, liver transplantation, chemotherapy and photodynamic therapy, the 5-year survival rate of only $\sim 5 \%$ remains low $(2,3)$. For advanced, inoperable BTC, palliative chemotherapy with cisplatin and gemcitabine results in a median survival rate of $\sim 1$ year $(4,5)$.

Chemokines are chemoattracting proteins, which bind to their respective receptors and thereby activate them. Chemokine receptor 4 (CXCR4) is a chemokine receptor, which specifically binds to chemokine ligand 12 (CXCL12). First identified on leukocytes, CXCR4 is expressed by several different cell types (6). It is important in organogenesis, and in tissue repair and regeneration in adults. Additionally, the expression of CXCR4 was identified in hematopoietic and non-hematopoietic tissue-committed stem cells (6-8).

The CXCR4/CXCL12 axis is important in adhesion, invasion, metastasis, migration and proliferation in various types of cancer, including breast cancer (9-13), small-cell lung cancer (14), head and neck squamous cell carcinoma (15), neuroblastoma (16), hepatocellular carcinoma (17) and colon cancer (18), and is generally associated with high aggressiveness and a poor prognosis. Several previous studies have suggested a role for the CXCR4/CXCL12 axis in BTC (19-23). Lee et al demonstrated that CXCL12 is associated with an advanced histological grade and nodal metastasis in gallbladder cancer, and observed increased anchorage-dependent, and -independent growth of gallbladder cancer cells in vitro, in a CXCR4-dependent manner (21). Leelawat et al compared the 
gene expression levels of cluster of differentiation (CD)24 ${ }^{-}$and CD24+ BTC cells, and revealed an upregulation of CXCR4 in the CD24+ ${ }^{+}$subpopulation (19). AMD3100 (Plerixafor) is a non-peptide antagonist of CXCR4, which inhibits CXCL12 binding and is currently used for hematopoietic stem cell mobilization and transplantation following chemotherapy of hematological malignancies $(24,25)$. The expression of CD24 is accompanied by poor clinical outcome in BTC, and AMD3100 inhibits the invasiveness of the CD24+ $4^{+}$subpopulation (19), therefore suggesting CXCR4 as a potential target for the treatment of BTC.

Taken together, CXCR4/CXCL12 are important in several types of cancer, potentially including BTC. Therefore, the aim of the present study was to examine the expression levels of CXCR4 in a larger panel of BTC cell lines $(n=8)$. Following confirmation of the expression levels, the effects of the AMD3100 CXCR4 antagonist, alone and in combination with the standard chemotherapeutic gemcitabine, on cell viability and anchorage-independent growth pattern were investigated.

\section{Materials and methods}

Reagents and cell culture. AMD3100 (Mozobil ${ }^{\mathrm{TM}}$ ) was supplied by Sanofi-Aventis (Paris, France) as a $20 \mathrm{mg} / \mathrm{ml}$ subcutaneous injection solution, and was stored at room temperature. Gemcitabine was obtained from the hospital pharmacy (Landesapotheke, Salzburger Landeskliniken), as a stock solution of $152 \mathrm{mM}$ in $\mathrm{H}_{2} \mathrm{O}$, and stored in aliquots at room temperature. Resazurin was purchased from Sigma-Aldrich (Vienna, Austria), dissolved in Dulbecco's phosphate-buffered saline (Sigma-Aldrich) and sterile filtered using a $0.2 \mu \mathrm{m}$ filter (Sarstedt, Nüxsmbrecht, Germany). A total of five bile duct carcinoma cell lines: CCSW-1 (G2), BDC (G4), EGI-1 (G3), SkChA-1 (G3), TFK-1 (G2); and three gallbladder cancer cell lines: MzChA-1 (G1), MzChA-2 (G2) and GBC (G1), were cultured in Dulbecco's modified Eagle's medium (DMEM; PAA Laboratories, Pasching, Austria), supplemented with $10 \%$ (v/v) fetal bovine serum (FBS; PAA Laboratories) - see $(26,27)$ for original references. Together, these were referred to as BTC cell lines (1). Subsequent experiments were performed using cells within 10 passages at seeding densities of $3.95 \times 10^{4}$ for BDC and MzChA-2, 4.74x10 $10^{4}$ for CCSW-1 and GBC), $5.53 \times 10^{4}$ for SkChA-1, $6.32 \times 10^{4}$ for EGI-1 and TFK-1, and $7.11 \times 10^{4}$ for $\mathrm{MzChA}-1$ (per $\mathrm{cm}^{2}$ of the culture dishes), in 10\% FBS-DMEM. Treatment with AMD3100 was performed in serum-free (sf)DMEM to avoid interaction of the drug with the serum ingredients.

Drug cytotoxicity. The dose- and cell line-dependent cytotoxicity of AMD3100 was investigated on the cells in 96-well microplates (Greiner Bio-One, Frickenhausen, Germany), using a resazurin assay (Sigma-Aldrich) and an Infinite M200 microplate reader (Tecan, Grödig, Austria) to assess the metabolic activity, as described previously $(27,28)$. For the cell line-dependent analysis, $400 \mu \mathrm{g} / \mathrm{ml}$ AMD3100 was added to the cells in sfDMEM for $72 \mathrm{~h}$, and the cell viability was normalized against untreated (sfDMEM only) samples. For dose-dependent analysis, a 1:2 dilution series ranging between 0.8 and $400.0 \mu \mathrm{g} / \mathrm{ml}$ of AMD3100 were added to SkCh-A1 cells in sfDMEM for $72 \mathrm{~h}$, and the viability was normalized against the untreated samples.

Anchorage-independent growth. The anchorage-independent growth of the SkChA-1 cells was assessed using the CytoSelect 96-well Cell Transformation assay (Cell Biolabs, Inc., San Diego, CA, USA) and an Infinite M200 microplate reader. The SkChA-1 cells were seeded at a density of $1 \times 10^{5}$ cells $/ \mathrm{ml}$ in a semi-solid agar, according to the manufacturer's instructions, and incubated with $100 \mu \mathrm{g} / \mathrm{ml}$ AMD3100 in DMEM for 14 days at $37^{\circ} \mathrm{C}$. Anchorage-independent growth was monitored using a light microscope (Motic AE31; Nikon Instruments, Melville, NY, USA) equipped with a CCD-1300B digital camera (Allied Vision Technologies/VDS, Vosskühler, Stadtroda, Germany), quantified using CyQuant GR dye and the growth was normalized against the untreated (DMEM only) samples.

Analysis of the mRNA expression of CXCR4. For mRNA expression analysis, the cells were grown in $35 \mathrm{~mm}$ cell culture dishes in DMEM for $72 \mathrm{~h}$. The total RNA was isolated using the Direct-zol ${ }^{\mathrm{TM}}$ RNA MiniPrep kit (Zymo Research, Irvine, CA, USA) with TRIzol Reagent (Ambion, Life Technologies, Vienna, Austria). The cDNA synthesis was performed through reverse transcription (RT), using $1 \mu \mathrm{g}$ isolated RNA and an ImProm-IITM Reverse Transcriptase system (Promega, Madison, WI, USA), according to the manufacturer's instructions. Quantification of the cDNA was determined through quantitative polymerase chain reaction (qPCR), using a GoTaq qPCR Master mix (Promega) and a ViiA7 real time PCR system (Applied Biosystems, Invitrogen Life Technologies, Carlsbad, CA, USA). cDNA (0.3 ng) was used for PCR and the following cycling conditions were used: $95^{\circ} \mathrm{C}$ for $2 \mathrm{~min}$ and 45 cylces of $95^{\circ} \mathrm{C}$ for $3 \mathrm{sec}$ and $60^{\circ} \mathrm{C}$ for $30 \mathrm{sec}$. The samples were measured at least three times, and subsequent melting curve analysis was performed for all the primers, to confirm the specificity of the PCR products. The samples were normalized against $\beta$-actin and the data were analyzed, according to the $\Delta \Delta \mathrm{Ct}$ method (29). The primer sequences used for RT-qPCR were as follows: $\beta$-actin, forward GCACTCTTCCAGCCTTCCTTCC and reverse TCTTTGCGGATGTCCACGTCAC and CXCR4 forward GTCATCTACACAGTCAACCTCTACAGCAGT and reverse AAGATGAAGTCGGGAATAGTCAGCAG.

Double treatments. The SkChA-1 cells were seeded into 96-well microplates and incubated with different concentrations of either AMD3100 $(200,100,50,25$ or $12.5 \mu \mathrm{g} / \mathrm{ml})$ or gemcitabine $(1000,500,250,125$ or $62.5 \mu \mathrm{M})$, or with combinations of these concentrations (constant $25 \mu \mathrm{g} / \mathrm{ml}$ AMD3100 combined with 1000, 500, 250, 125 and $62.5 \mu \mathrm{M}$ gemcitabine or constant gemcitabine $(500 \mu \mathrm{M})$ combined with 200,100 , 50, 25 and $12.5 \mu \mathrm{g} / \mathrm{ml}$ AMD3100). Cell viability was measured using a resazurin assay and an Infinite M200 microplate reader. The obtained data were entered into CompuSyn software (version 1.0) to calculate the combination index (CI), in which drug combinations leading to a $\mathrm{CI}>1.1$ were considered to be antagonistic, and CI values $<0.9$ were considered to be synergistic (30).

Statistical analyses. Unless otherwise indicated, all data are presented as the mean \pm standard error of the mean, of at 
least three biological replicates. An unpaired Student's t-test was used for calculation of the significance of differences in anchorage-independent growth. A paired Student's t-test was performed for calculation of the significance of the effect of AMD3100 on cell viability. All calculations were performed using OriginPro 9.1 software (OriginLab, Northampton, MA, USA). $\mathrm{P}<0.05$ was considered to indicate a statistically significant difference.

\section{Results}

Expression of CXCR4 in the BTC cell lines. The present study confirmed the mRNA expression levels of CXCR4 in eight BTC cell lines using RT-qPCR. The expression values differed between the cell lines, with SkChA-1 exhibiting the highest expression levels of CXCR4 (Fig. 1A).

Effect of treatment with AMD3100 on overall cell viability. The present study subsequently investigated whether the addition of the CXCR4 antagonist, AMD3100, had an effect on the cell viability of the CXCR4-expressing cell lines. The cells were treated with $400 \mu \mathrm{g} / \mathrm{ml}$ AMD3100 for $72 \mathrm{~h}$. The results revealed that the addition of AMD3100 led to a reduction in cell viability in seven of the cell lines, with no effect for CCSW-1. Significant decreases of 20-30\% were observed in the GBC, MzChA-1, SkChA-1 and TFK-1 cell lines (Fig. 1B). Although no correlation was observed between the expression levels of CXCR4 and the reduction in cell viability by AMD3100 (data not shown), the most marked effect of AMD3100 on cell viability was observed in the SkChA-1 cells which also exhibited the highest mRNA expression levels of CXCR4.

To investigate the dose-dependent effects of AMD3100 on $\mathrm{SkChA}-1$ cells, a dilution series ranging between 0.8 and $400.0 \mu \mathrm{g} / \mathrm{ml}$ was used, with cells incubated with AMD3100 for $72 \mathrm{~h}$ at $37^{\circ} \mathrm{C}$. As shown in Fig. 1C, treatment with AMD3100 reduced the overall cell viability in a dose-dependent manner, with a significant reduction of $\sim 20 \%$ at concentrations $>100 \mu \mathrm{g} / \mathrm{ml}$ (Fig. 1C).

Taken together, treatment with AMD3100 reduced the cell viability in seven of the eight BTC cell lines assessed. As the most marked decline in cell viability was observed in the $\mathrm{SkChA-1}$ cells, this cell line was selected for use in the subsequent experiments.

Combined treatment of AMD3100 and gemcitabine. The present study subsequently investigated whether the combination of AMD3100 with gemcitabine, a standard chemotherapeutic drug, further reduced the viability of the SkChA-1 cells, and whether these drugs acted synergistically. The results suggested that at least two combinations: $50 \mu \mathrm{g} / \mathrm{ml}$ AMD3100 with $500 \mu \mathrm{M}$ gemcitabine, and $12.5 \mu \mathrm{g} / \mathrm{ml}$ AMD3100 with $500 \mu \mathrm{M}$ gemcitabine, demonstrated a synergistic cytotoxic effect on the SkChA-1 cells (Fig. 2). Experiments using a combination of AMD3100 and cisplatin revealed no synergistic effect (data not shown).

Effect of AMD3100 on anchorage-independent growth. Anchorage-independent growth is a hallmark of increased tumor aggressiveness, metastatic potential and cancer
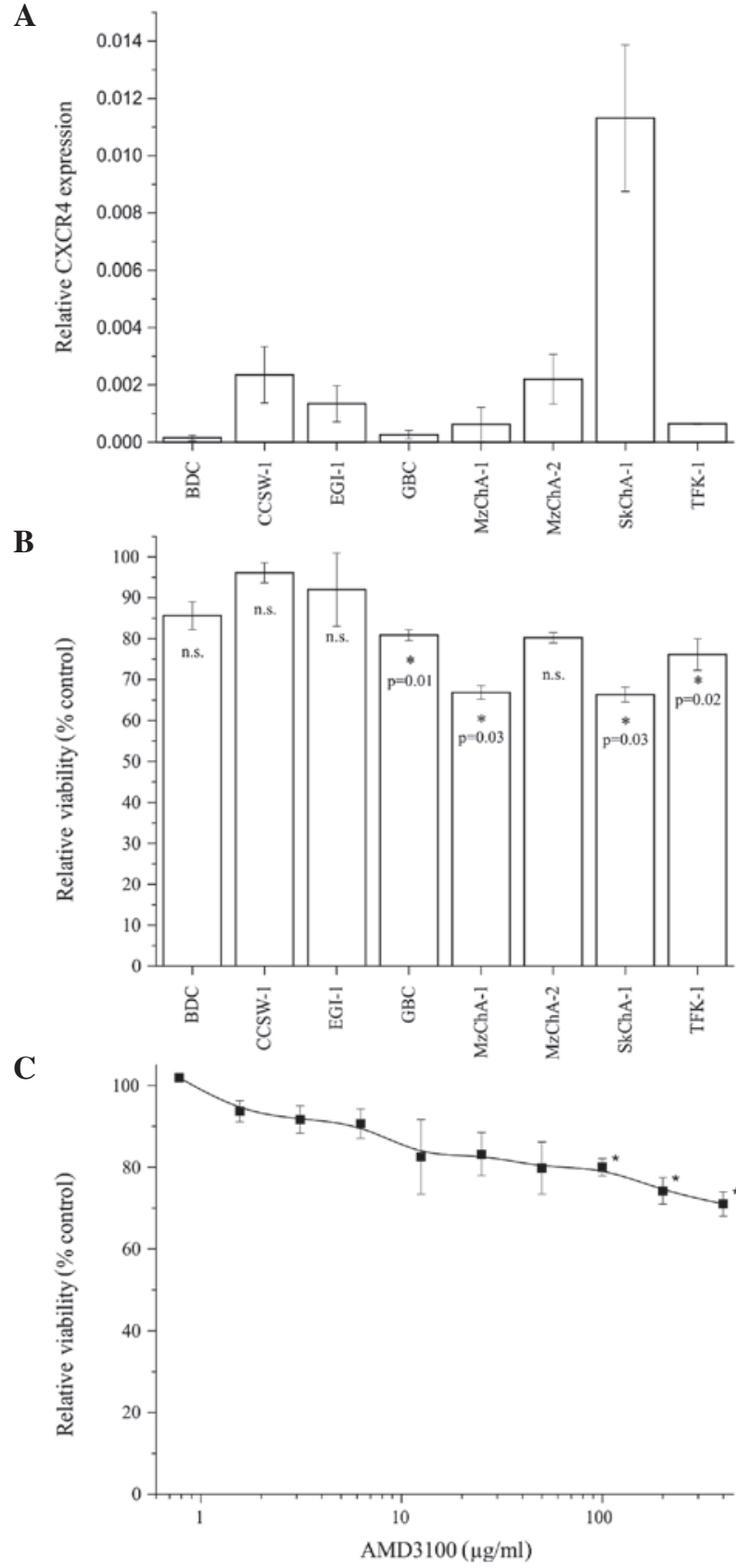

Figure 1. Expression levels of CXCR4 and the cytotoxic effects of AMD3100 on BTC cell lines. (A) BTC cells were analyzed for the mRNA expression of CXCR4 using reverse transcription-quantitative polymerase chain reaction. The data were normalized against $\beta$-actin and are expressed as the mean \pm standard error of the mean. (B) Effect of treatment with AMD3100 $(400 \mu \mathrm{g} / \mathrm{ml})$ on cell viability in the BTC cell lines following incubation for $72 \mathrm{~h}$. The data are expressed as the percentage of untreated control wells, as the mean \pm standard error of the mean. (C) Dose-dependent effect of AMD3100 on SkChA-1 cell viability following incubation for $72 \mathrm{~h}$. The data are expressed as the percentage of untreated controls, as the mean \pm standard error of the mean. CXCR4, chemokine receptor 4; BTC, biliary tract cancer; ns, not significant.

stem cell (CSC) characteristics (31). In order to assess the effect of AMD3100 on anchorage-independent growth, the $\mathrm{SkChA}-1$ cells were seeded into semisolid agar and incubated for 14 days at $37^{\circ} \mathrm{C}$, in the presence or absence of AMD3100. Treatment with AMD3100 significantly inhibited anchorage-independent growth in the SkChA-1 cells, leading to a reduction of $\sim 50 \%$ (Fig. 3A). Representative images of 


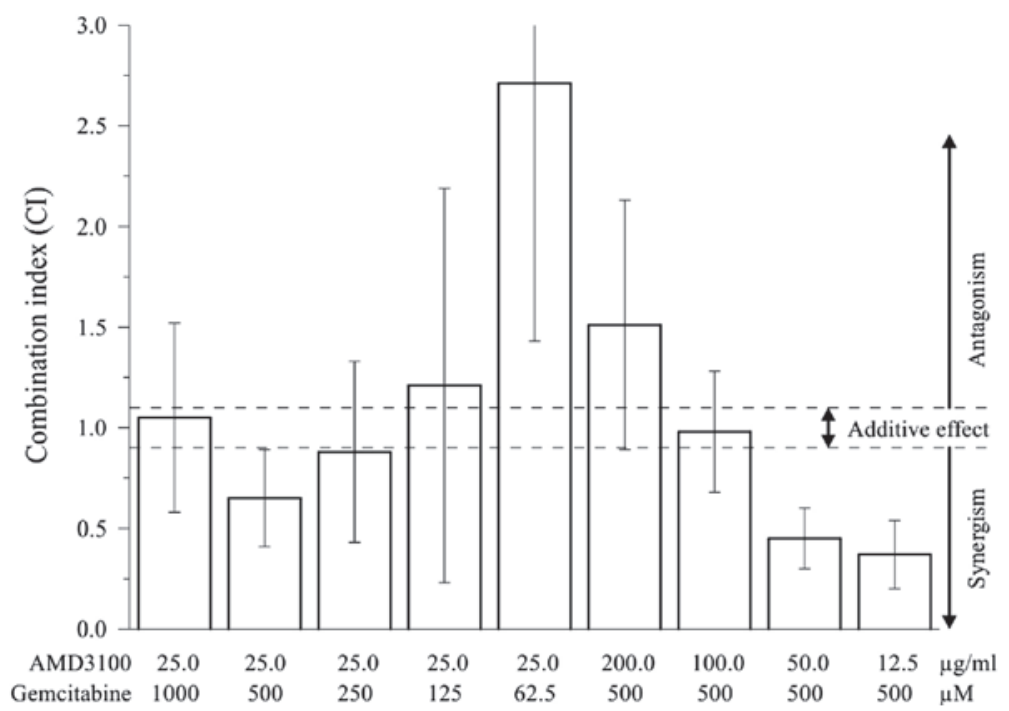

Figure 2. Combined treatment with AMD3100 and gemcitabine on SkChA-1 cells. The SkChA-1 cells were incubated for $72 \mathrm{~h}$ with different concentrations and combinations of AMD3100 and gemcitabine. CompuSyn software was used to calculate the CI. CI values $<0.9$ indicated synergistic effects and CI values between 0.9 and 1.1, or $>1.1$ indicated additive or antagonistic effects (30). The data are expressed as the mean \pm standard error of the mean. CI, combination index.
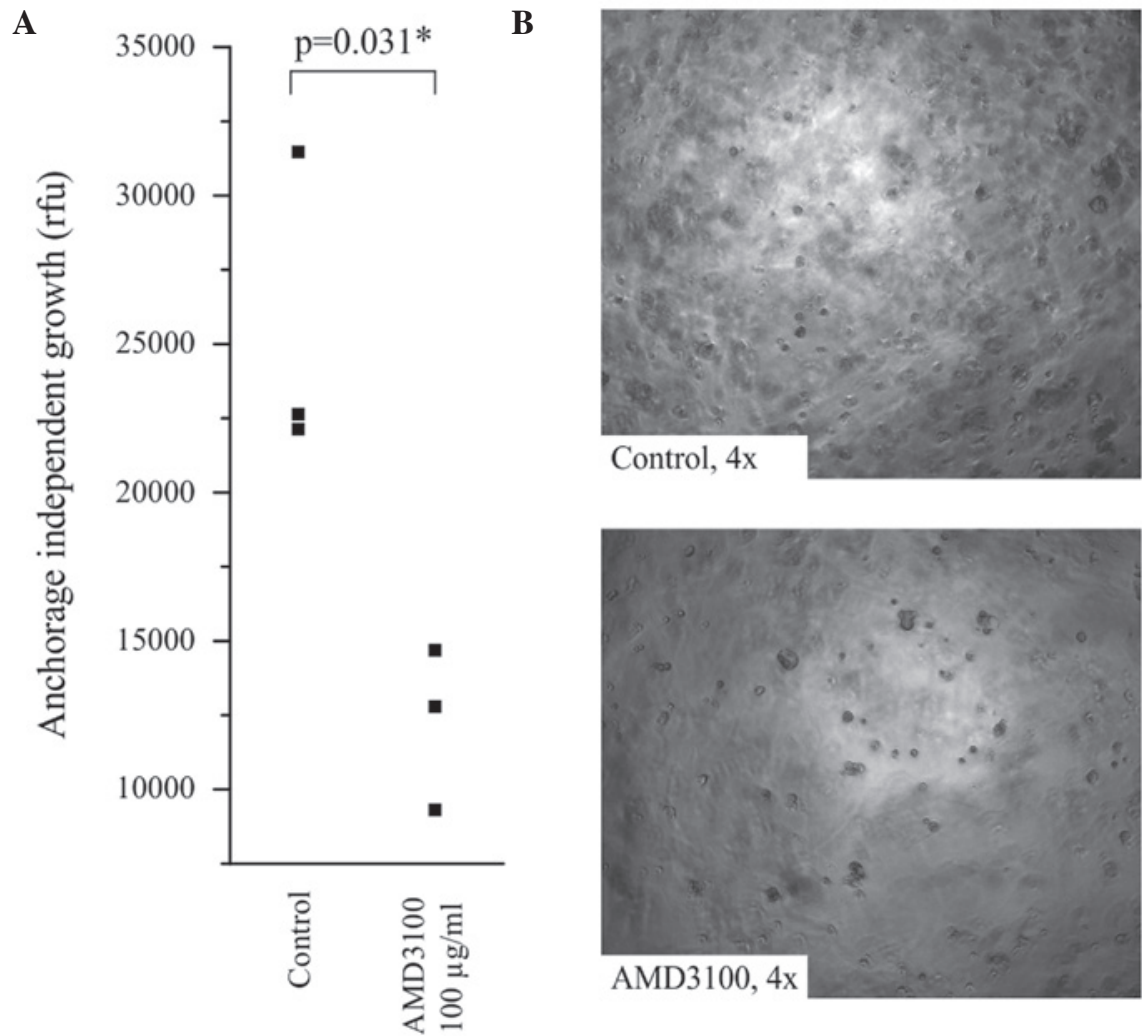

Figure 3. Effect of AMD3100 on anchorage-independent growth of SkChA-1 cells. (A) SkChA-1 cells were incubated in semisolid agar for 14 days in the absence or presence of $100 \mu \mathrm{g} / \mathrm{ml}$ AMD3100. Anchorage-independent growth was quantified using CyQuant GR dye. (B) Representative images of the untreated (control) SkChA-1 cells and the SkChA-1 cells treated with AMD3100. rfu, relative fluorescent unit.

SkChA-1 cells with and without AMD3100 are shown in Fig. 3B and indicated a reduction in cell aggregates.

\section{Discussion}

The high mortality rates and poor prognosis of BTC underlines the requirement for novel therapeutic approaches. The CXCR4 chemokine receptor and its ligand, CXCL12, are involved in the regulation of tissue-committed stem cells (6-8). Furthermore, these proteins are involved in cancer cell invasion, metastasis, migration and proliferation (9-18). CXCR4 is expressed in several types of cancer $(7,8)$, including BTC $(19,22,23)$, and its expression correlates with high levels of aggressiveness and a poor prognosis (7). Previous studies have demonstrated the 
involvement of CXCR4 signaling in the migration and invasion of BTC cells, which can be reduced by the pharmacological inhibition of CXCR4 using AMD3100 (19,22,23).

In accordance with these results, the present study detected the mRNA expression of CXCR4 in eight BTC cell lines, to a variable extent, indicating that this signaling axis exhibits different activities in different cell lines. In the BDC and GBC cell lines, the mRNA expression levels of CXCR4 were almost undetectable, whereas those of CXCR4 were highest in the SkChA-1 cells, compared with the other cell lines.

Treatment of the cell lines with a high concentration $(400 \mu \mathrm{g} / \mathrm{ml})$ of the AMD3100 CXCR4 antagonist for $72 \mathrm{~h}$ reduced cell viability in seven cell lines, with no effect in the CCSW-1 cells, of which significant reductions were observed in the GBC, MzChA-1, SkChA-1 and TFK-1 cells. Since SkChA-1 not only demonstrated the highest expression levels of CXCR4, but also the most marked decline in cell viability following treatment with AMD3100, the present study assessed the dose-dependent $(0.78-400 \mu \mathrm{g} / \mathrm{ml})$ effect of AMD3100 on the cell viability of the SkChA-1 cell line. A dose-dependent reduction in viability following $72 \mathrm{~h}$ AMD3100 treatment was confirmed, with significant reductions observed at concentrations $>100 \mu \mathrm{g} / \mathrm{ml}$. These effects were possibly caused by a slowdown of proliferation, rather than actual cytotoxicity, as no previous reports have provided evidence to suggest the induction of cell death following the inhibition of CXCR4. For example, treatment of a cholangiocarcinoma cell line with AMD3100 revealed no effect on cell viability (19). Although the present study used a higher concentration of AMD3100 compared with (19), it is also possible that, due to the heterogeneity of BTC, cell lines respond differentially to the inhibition of CXCR4. Previous studies using BTC cell lines demonstrated an inhibitory effect on cell migration following the inhibition of CXCR4 receptors, while the addition of the CXCL12, SDF-1a ligand increases the proliferative capacity of BTC cells $(22,23)$. In the present study, no correlation was observed between the expression of CXCR4 and the effect of AMD3100 on cell viability.

A significant reduction of $50 \%$ was observed in the anchorage-independent growth of the SkChA-1 cells following treatment with AMD3100. This is particularly interesting, as this assay is considered a functional assessment of stemness characteristics in the CSC theory (31). Therefore, subsequent investigations into the CSC-specific effects of the pharmacological inhibition of CXCR4 are required. In line with this theory, CXCR4 is upregulated in the CD24+ $4^{+}$subpopulation, and the expression of this surface molecule is associated with a poor clinical outcome (19) and has been suggested as a marker for putative CSCs in BTC (32).

Gemcitabine combined with cisplatin is the current standard chemotherapy for patients with advanced BTC $(4,5)$. The present study examined the possible synergistic effects of each of these drugs combined with AMD3100 on SkChA-1 cell viability. Combination with cisplatin revealed no synergistic effect (data not shown), whereas several combinations of gemcitabine with AMD3100 indicated a clear synergistic effect of those two drugs (30). Notably, at a constant gemcitabine concentration $(500 \mu \mathrm{M})$ the synergistic effect was more pronounced as the concentrations of AMD3100 decreased, with the lowest CI value being $12.5 \mu \mathrm{g} / \mathrm{ml}$. This result suggested that inhibition of CXCR4 combined with gemcitabine may be a suitable treatment strategy, and is in line with a report by Singh et al, which demonstrated that the inhibition of CXCR4 using AMD3100 eliminated gemcitabine resistance in pancreatic cancer cells (33).

In conclusion, the present study demonstrated that CXCR4 was expressed in BTC cell lines and that the inhibition of this receptor affected anchorage-dependent and anchorage-independent growth. Furthermore, it was revealed for the first time, to the best of our knowledge, that the combination of AMD3100 with standard chemotherapeutic gemcitabine may be a promising optional therapeutic approach for BTC.

\section{Acknowledgements}

This study was supported by funds from the Oesterreichische Nationalbank (Anniversary fund no. 14842) and the research fund of the Paracelsus Medical University Salzburg (no. A12-02-006-KIE).

\section{References}

1. de Groen PC, Gores GJ, LaRusso NF, Gunderson LL and Nagorney DM: Biliary tract cancers. N Engl J Med 341: 1368-1378, 1999

2. Braconi $\mathrm{C}$ and Patel T: Cholangiocarcinoma: new insights into disease pathogenesis and biology. Infect Dis Clin North Am 24: 871-884, vii, 2010

3. Malhi $\mathrm{H}$ and Gores GJ: Cholangiocarcinoma: modern advances in understanding a deadly old disease. J Hepatol 45: 856-867, 2006.

4. Valle J, Wasan H, Palmer DH, et al: Cisplatin plus gemcitabine versus gemcitabine for biliary tract cancer. N Engl J Med 362: 1273-1281, 2010.

5. Valle JW, Furuse J, Jitlal M, et al: Cisplatin and gemcitabine for advanced biliary tract cancer: a meta-analysis of two randomised trials. Ann Oncol 25: 391-398, 2014.

6. Furusato B, Mohamed A, Uhlén M and Rhim JS: CXCR4 and cancer. Pathol Int 60: 497-505, 2010.

7. Kucia M, Reca R, Miekus K, et al: Trafficking of normal stem cells and metastasis of cancer stem cells involve similar mechanisms: pivotal role of the SDF-1-CXCR4 axis. Stem Cells 23: 879-894, 2005.

8. Zlotnik A: Chemokines and cancer. Int J Cancer 119: 2026-2029, 2006.

9. Allinen M, Beroukhim R, Cai L, et al: Molecular characterization of the tumor microenvironment in breast cancer. Cancer Cell 6: 17-32, 2004.

10. Fernandis AZ, Prasad A, Band H, Klösel R and Ganju RK: Regulation of CXCR4-mediated chemotaxis and chemoinvasion of breast cancer cells. Oncogene 23: 157-167, 2004.

11. Lapteva N, Yang AG, Sanders DE, Strube RW and Chen SY: CXCR4 knockdown by small interfering RNA abrogates breast tumor growth in vivo. Cancer Gene Ther 12: 84-89, 2005.

12. Liang Z, Yoon Y, Votaw J, Goodman MM, Williams L and Shim H: Silencing of CXCR4 blocks breast cancer metastasis. Cancer Res 65: 967-971, 2005.

13. Muller A, Homey B, Soto H, et al: Involvement of chemokine receptors in breast cancer metastasis. Nature 410: 50-56, 2001.

14. Burger M, Glodek A, Hartmann T, et al: Functional expression of CXCR4 (CD184) on small-cell lung cancer cells mediates migration, integrin activation, and adhesion to stromal cells. Oncogene 22: 8093-8101, 2003.

15. Samara GJ, Lawrence DM, Chiarelli CJ, et al: CXCR4-mediated adhesion and MMP-9 secretion in head and neck squamous cell carcinoma. Cancer Lett 214: 231-241, 2004.

16. Geminder H, Sagi-Assif O, Goldberg L, et al: A possible role for CXCR4 and its ligand, the CXC chemokine stromal cell-derived factor-1, in the development of bone marrow metastases in neuroblastoma. J Immunol 167: 4747-4757,2001.

17. Schimanski CC, Bahre R, Gockel I, et al: Dissemination of hepatocellular carcinoma is mediated via chemokine receptor CXCR4. Br J Cancer 95: 210-217, 2006. 
18. Ottaiano A, di Palma A, Napolitano M, et al: Inhibitory effects of anti-CXCR4 antibodies on human colon cancer cells. Cancer Immunol Immunother 54: 781-791, 2005.

19. Leelawat K, Keeratichamroen S, Leelawat S and Tohtong R: CD24 induces the invasion of cholangiocarcinoma cells by upregulating CXCR4 and increasing the phosphorylation of ERK1/2. Oncol Lett 6: 1439-1446, 2013.

20. Leelawat K, Leelawat S, Narong S and Hongeng S: Roles of the MEK1/2 and AKT pathways in CXCL12/CXCR4 induced cholangiocarcinoma cell invasion. World J Gastroenterol 13: 1561-1568, 2007.

21. Lee HJ, Lee K, Lee DG, et al: Chemokine (C-X-C motif) ligand 12 is associated with gallbladder carcinoma progression and is a novel independent poor prognostic factor. Clin Cancer Res 18: 3270-3280, 2012.

22. Gentilini A, Rombouts K, Galastri S, et al: Role of the stromal-derived factor-1 (SDF-1)-CXCR4 axis in the interaction between hepatic stellate cells and cholangiocarcinoma. J Hepatol 57: 813-820, 2012.

23. Okamoto K, Tajima H, Nakanuma S, et al: Angiotensin II enhances epithelial-to-mesenchymal transition through the interaction between activated hepatic stellate cells and the stromal cell-derived factor-1/CXCR4 axis in intrahepatic cholangiocarcinoma. Int J Oncol 41: 573-582, 2012

24. Girbl T, Lunzer V, Greil R, Namberger K and Hartmann TN: The CXCR4 and adhesion molecule expression of CD34+ hematopoietic cells mobilized by 'on-demand' addition of plerixafor to granulocyte-colony-stimulating factor. Transfusion 54: 2325-2335, 2014.

25. Fruehauf S: Current Clinical Indications for Plerixafor. Transfusion medicine and hemotherapy : offizielles Organ der Deutschen Gesellschaft fur Transfusionsmedizin und Immunhamatologie 40: 246-250, 2013.
26. Kiesslich T, Alinger B, Wolkersdörfer GW, Ocker M, Neureiter D and Berr F: Active Wnt signalling is associated with low differentiation and high proliferation in human biliary tract cancer in vitro and in vivo and is sensitive to pharmacological inhibition. Int J Oncol 36: 49-58, 2010.

27. Wachter J, Neureiter D, Alinger B, et al: Influence of five potential anticancer drugs on wnt pathway and cell survival in human biliary tract cancer cells. Int J Biol Sci 8: 15-29, 2012.

28. Kiesslich T, Neureiter D, Alinger B, et al: Uptake and phototoxicity of meso-tetrahydroxyphenyl chlorine are highly variable in human biliary tract cancer cell lines and correlate with markers of differentiation and proliferation. Photochem Photobiol Sci 9: 734-743, 2010.

29. Livak KJ and Schmittgen TD: Analysis of relative gene expression data using real-time quantitative $\mathrm{PCR}$ and the 2(-Delta Delta C(T)) Method. Methods 25: 402-408, 2001.

30. Chou TC: Theoretical basis, experimental design, and computerized simulation of synergism and antagonism in drug combination studies. Pharmacol Rev 58: 621-681, 2006.

31. Charafe-Jauffret E, Ginestier C and Birnbaum D: Breast cancer stem cells: tools and models to rely on. BMC Cancer 9: 202, 2009.

32. Wang M, Xiao J, Shen M, et al: Isolation and characterization of tumorigenic extrahepatic cholangiocarcinoma cells with stem cell-like properties. Int J Cancer 128: 72-81, 2011.

33. Singh S, Srivastava SK, Bhardwaj A, Owen LB and Singh AP: CXCL12-CXCR4 signalling axis confers gemcitabine resistance to pancreatic cancer cells: a novel target for therapy. Br J Cancer 103: 1671-1679, 2010. 